\title{
Regulation of Key Genes for Milk Fat Synthesis in Ruminants
}

\author{
Tong $\mathrm{Mu}^{\dagger}$, Honghong $\mathrm{Hu}^{\dagger}$, Yanfen Ma, Xiaofang Feng, Juan Zhang and Yaling $\mathrm{Gu}^{*}$ \\ School of Agriculture, Ningxia University, Yinchuan, China
}

Milk fat is the most important and energy-rich substance in milk and plays an important role in the metabolism of nutrients during human growth and development. It is mainly used in the production of butter and yogurt. Milk fat not only affects the flavor and nutritional value of milk, but also is the main target trait of ruminant breeding. There are many key genes involve in ruminant milk fat synthesis, including ACSS2, FASN, ACACA, CD36, ACSL, SLC27A, FABP3, SCD, GPAM, AGPAT, LPIN, DGAT1, PLIN2, XDH, and BTN1A1. Taking the de novo synthesis of fatty acids (FA) and intaking of long-chain fatty acids (LCFA) in blood to the end of lipid droplet secretion as the mainline, this manuscript elucidates the complex regulation model of key genes in mammary epithelial cells (MECs) in ruminant milk fat synthesis, and constructs the whole regulatory network of milk fat synthesis, to provide valuable theoretical basis and research ideas for the study of milk fat regulation mechanism of ruminants.

Annalisa Terranegra,

Sidra Medicine, Qatar

Reviewed by:

Xudong Sun,

Heilongjiang Bayi Agricultural

University, China

Wangsheng Zhao,

Southwest University of Science and

Technology, China

*Correspondence:

Yaling Gu

guyl@nxu.edu.cn

Keywords: ruminants, milk fat, regulatory factors, genes, synthesis

\section{INTRODUCTION}

The demand for high-quality milk is increasing yearly worldwide, and the quality of milk has become the focus of consumers' common concern (1). Milk quality is mainly influenced by factors such as herd genetic structure, reproductive performance and feeding management level, and is also closely related to the main components in milk. Milk fat is rich in important energy substances required by humans and is a major component in the production of butter and yogurt. As a major target trait in dairy breeding, milk fat not only affects the flavor of milk and the nutritional value of milk, but is also one of the core competitiveness marks of the dairy industry (2). Studies have shown that milk fat plays a crucial role in human growth and development (3), the content and proportion of milk fat required by different consumer groups vary with children having a higher requirement for milk fat during their growth. Since 95\% of milk fat is composed of saturated long-chain fatty acids (LCFA), which is associated with cardiovascular disease (4), older adults and people with diabetes, obesity and cardiovascular disease are more likely to choose low-fat or nonfat dairy products (5). Overall, the milk fat content, quality and fatty acid composition of milk are particularly important for human health. Therefore, improving milk quality and production efficiency is a top priority. Usually, the synthesis of milk fat can be achieved by combining genetic improvement with good management, however, following the discovery of DNA and advances in molecular biology techniques, it is clear that manipulation of DNA transcription and posttranscriptional regulation is a powerful means of influencing phenotypic outcomes. In summary, to provide a valuable theoretical basis and reference for the study of ruminant milk fat regulation mechanism, we were reviewed in this manuscript based on the mainline from fatty acid (FA) synthesis to the end of lipid droplet secretion, this manuscript expounds on the complex regulation mode of key genes in mammary epithelial cells (MECs) of ruminant milk fat synthesis. 


\section{SYNTHESIS OF MILK FAT IN RUMINANTS}

Milk and dairy products are considered important the foods as early as 4,000 B.C., as evidenced by the petroglyphs of the Sahara Desert. Most scientific advances build the path of knowledge in very small increments, and the same is true of advances in lactation biology. The biology of bovine mammary lactation made great progress in the twentieth century, such as establishing the structure-function relationship between the MECs and the mammary gland, identifying the biochemical pathways of milk synthesis, and elucidating the role of hormones in the development and functional regulation of the mammary gland (6). Among these, milk fat synthesis, the formation and secretion of milk droplets are of particular interest, which affects the manufacturing characteristics and sensory quality of milk and dairy products (7). Early studies (1960-1980) in ruminants defined and quantified the main modes of mammary gland fat metabolism, including de novo synthesis of FA and LCFA uptake in the blood (6). The emergence of real-time fluorescence quantitative reverse transcriptase polymerase chain reaction (qRT-PCR) accelerated researchers' understanding of milk fat regulation, while high-throughput sequencing technology brought the research of milk fat synthesis into a new stage (8). Nearly $99 \%$ of the milk fat is the form of lipid droplets in the organism of ruminants, triglycerides (TAG) account for about $98 \%$ of the lipid droplets, and the remaining $2 \%$ are monoglycerides, diacylglycerol, cholesterol and free FA (9). Milk fat synthesis in ruminants is a complex molecular regulatory network, including de novo synthesis of FA, LCFA uptake in blood, LCFA transport and desaturation, TAG synthesis and lipid droplet secretion (10) (Figure 1).

\section{DE NOVO SYNTHESIS OF FA}

Acetic acid (acetate) and $\beta$-hydroxybutyric acid (BHBA) enter the cell membrane by passive diffusion in FA de novo synthesis, which is less than the flip-flop and protein-mediated uptake of LCFA (11). Acetyl-CoA carboxylase (ACACA), fatty acid synthase (FASN) and acyl-CoA synthetase short-chain family member 2 (ACSS2) were significantly up-regulated during lactation, and the de novo synthesis pathway of FA depended on these three key enzymes (12). Acetic acid and BHBA are activated in MECs by ACSS2 and converted to acetyl-CoA (acetyl-CoA) by binding to pyruvate. Acetyl-CoA is carboxylated by ACACA to form malonyl-CoA, medium-chain fatty acids (MCFA) or LCFA are synthesized under the action of FASN (carried out in cytosol) (13).

\section{POSITIVE REGULATION OF DE NOVO SYNTHESIS OF FA}

\section{Acetate and BHBA Promote Milk Fat Synthesis}

Acetate and BHBA are the main substrates for the de novo synthesis of FA in ruminants, which are essential for meeting energy requirements $(70 \%)$ and milk fat synthesis of dairy cows (14). Research that nutritional strategies to increase rumen acetate uptake in dairy cows can increase milk fat through increase synthesis of FA (15). At the molecular level, the addition of different concentrations of acetate and BHBA increase the relative abundance of TAG content and lipogenic genes in bovine mammary epithelial cells (BMECs) in vitro (16), lipogenic genes include FASN, peroxisome proliferator-activated receptor $\alpha$ and $\gamma$ (PPARA, PPARG) and phosphatidyl phosphatase 1 (LPIN1) (17). In addition, Acetate regulates milk lipid synthesis through the mTOR/eIF4E signaling pathway in BMECs (18). Thus, acetate and BHBA are not only the main substrates for de novo synthesis of FA in ruminants, but also have a significant positive regulatory role in milk fat synthesis.

\section{SREBP1}

SREBP1 is synthesized as an inactive precursor in the endoplasmic reticulum and forms a complex with the SREBF partner (SCAP), which activates the adipogenic gene after being hydrolyzed in the Golgi apparatus and indirectly regulate milk fat synthesis (19). Silencing of SREBP1 reduces the mRNA abundance of ACACA and FASN in BMECs (4065\%) (20) and significantly down-regulates gene expression levels of ACSS2 (21), which is partly dependent on the enhancement of rapamycin target protein (mTOR) pathway. The regulatory functions of SREBP1 were also confirmed in goat mammary gland epithelial cells (GMECs) and found that AKT serine/threonine kinase (AKT1) phosphorylation has a key role in SREBP1 by activating the mTOR pathway $(22,23)$. To sum up, SREBP1 has a positive regulatory effect on the de novo synthesis of FA in ruminants and depends on the activation of mTOR pathway.

\section{RPL8, Ubiquitination and LXR Regulate FA de novo Synthesis Through SREBP1}

Genome-wide association analysis (GWAS) reveals an important SNP (g.-931G $>$ T) in the promoter region of ribosomal protein L8 (RPL8) in mammary tissue of lactating cows, which is strongly correlated with high expression of RPL8 (23). The expression levels of FASN, ACACA and SREBP1 in BMECs are significantly reduced when RPL8 is silenced (24). RPL8 may indirectly regulate FA de novo synthesis by down-regulating the expression of SREBP1 based on the positive regulatory effect of SREBP1 on FASN and ACACA (20), but the specific regulatory mechanism needs to be further verified. In addition, SREBP1 can be phosphorylated by recruiting glycogen synthase kinase GSK3 and then recruit ubiquitin ligase SCF-Fbw7 to be ubiquitinated and degraded by ubiquitin-proteasome system (UPS) when SREBP1 connects the target gene $(25,26)$. The expression of ACACA gene was significantly down-regulated after inhibiting the activity of UPS in BMECs, while the FASN gene was on the contrary (27). It is suggested that ubiquitin could regulate the expression of ACACA and FASN by regulating the transcription factor SREBP1 through the UPS pathway in the de novo synthesis of FA. Liver $\mathrm{X}$ receptor (LXR) is a member of the nuclear receptor superfamily, including $\operatorname{LXR} \alpha$ and $\operatorname{LXR} \beta$, which is widely expressed in lung, liver, brain and mammary gland (28). Gene expression of LXR $\alpha$ and SREBP1 was increased in a 


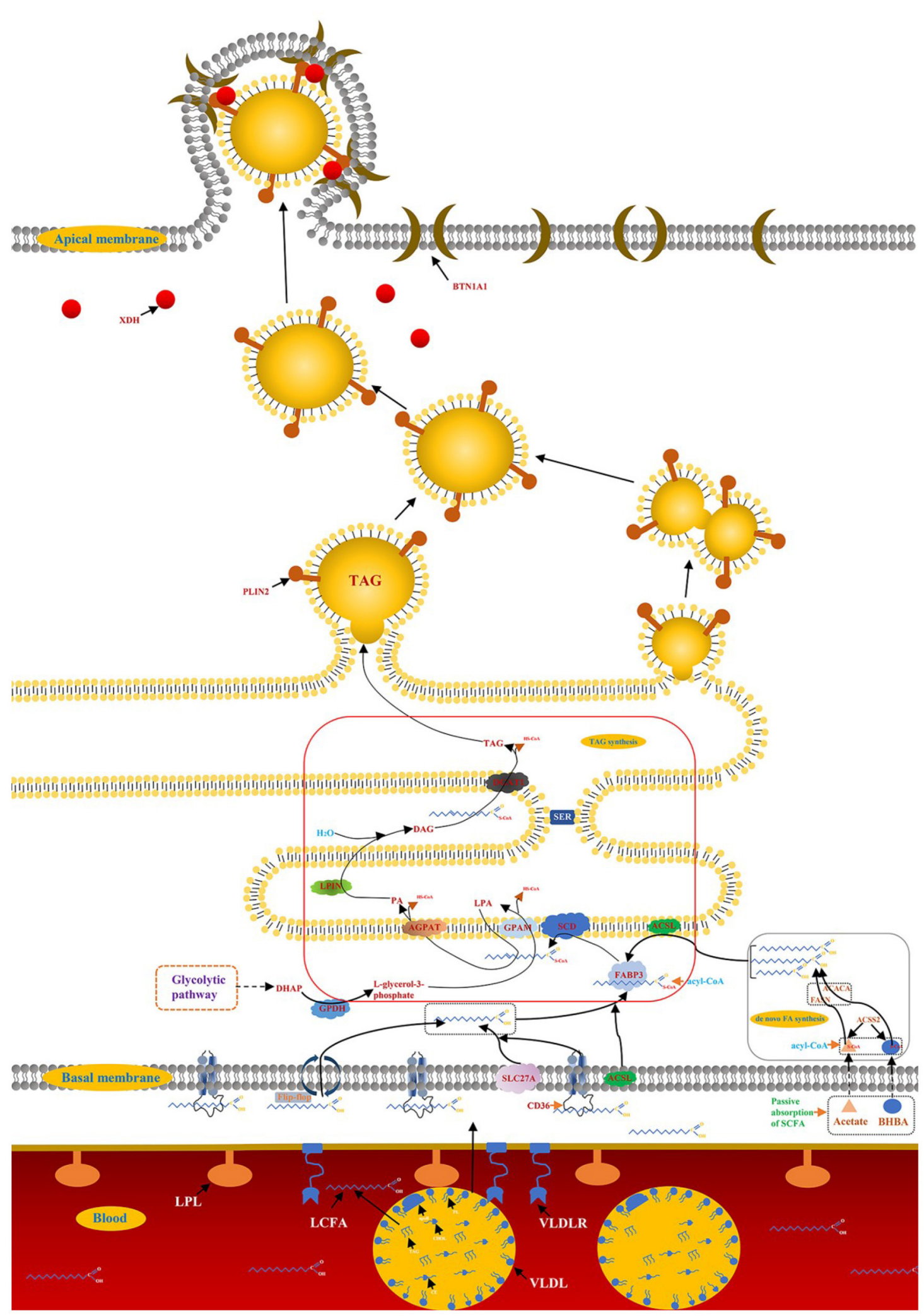

FIGURE 1 | Synthesis of milk fat in ruminants. A detailed description of the model is reported in the manuscript. 
dose-dependent manner by different concentrations of T0901317 in GMECs, activation of LXR $\alpha$ also significantly increased the expression of FASN, ACACA and ACSS2, TAG content increased by more than $20 \%$ (29). In addition, SREBP1 activity and FASN gene expression were significantly upregulated in GMECs when the forkhead box protein O1 (Foxo1) gene was knocked down (30). Thus, LXR in the goat mammary gland positively regulates FA de novo synthesis in an SREBP1-dependent manner, which may be partially repressed by Foxo1.

\section{PPARs}

PPARs, transcription factors, are activated by nuclear receptor super-family ligands, including PPARA, PPARG, and peroxidase proliferation-activated receptor $\delta$ (PPARD). PPARA and PPARG are expressed in liver and fat, respectively, while PPARD is widely expressed in fat, stomach, liver and lungs (31). PPARs have been reported to play important regulatory role in adipocyte differentiation, adipose metabolism and inflammation (32). PPARG positively regulates gene expression of FASN and ACSS2 in GMECs (33), which is consistent with the findings in buffalo and dairy cattle $(34,35)$. PPARD in rodents is mainly related to the catabolism of FA. The expression of PPARD at peak lactation is lower than that in dry period in the goat mammary gland. Overexpression PPARD does not affect the gene expression of ACACA and FASN, but inhibition PPARD significantly downregulates the gene expression of FASN, which indicate that PPARD plays an important role in the dynamic balance of MECs in ruminants (36). In addition, PPARA activated by agonist WY14643 in primary GMECs upregulated FASN expression by 1.1fold (37). The above studies suggest a positive regulatory role of the PPARs family in FA de novo synthesis and find that the function of PPARD may be weaker than PPARG and PPARA. However, higher expression of transcription factors not play a significant role, vice versa. As mentioned above, the presence of WY-14643 agonist is more critical.

\section{THRSP}

Thyroid hormone responsive spot (THRSP) is a key protein for new adipogenesis in non-ruminants. The expression of THRSP was the highest in subcutaneous fat of ruminants, the expression of THRSP during lactation was higher than that of in dry period in mammary gland (38). THRSP can positively regulates FASN in GMECs (39), however, ACACA activated by THRSP requires binding to spot-related protein (Spot14-R) (40). In addition, the positive regulatory effect of THRSP on the de novo synthesis of milk fat is inhibited by trans-10, cis- 12 conjugated linoleic acid (t10c12-CLA) (41).

\section{CIDEA and CIDEC}

The cell death inducing DFFA like effector A (CIDEA), a lipid droplet-related protein, is highly expressed in adipose tissue (42), which can promote liver lipid accumulation and the development of fatty liver (43). The expression level of CIDEA is high in mammary gland of lactating mice (44). Overexpression CIDEA and non-esterified fatty acid (NEFA) significantly up-regulated the expression gene of FASN and ACACA in BMECs and increased the content of TAG, the promoting effect of NEFA on milk fat synthesis disappeared after knockout of CIDEA, suggesting that high levels of NEFA promote FA de novo synthesis and milk fat secretion by stimulating CIDEA expression (45). Interestingly, interference RPL8 significantly upregulate the gene expression of CIDEA and decrease the mRNA abundance of FASN and ACACA, suggesting that the positive regulatory effect of RPL8 on FASN and ACACA may be stronger than the negative regulatory effect on CIDEA (24). Cell death-inducing DFF45like effector c (CIDEC) is also a lipid droplet-associated protein located in lipid droplets and highly expressed in white and brown adipose tissue (46). CIDEC shares the same regulatory pattern as CIDEA and has been positively regulated ACSS2 (47). To sum up, both CIDEA and CIDEC play a positive role in the de novo synthesis of milk fat.

\section{Other Genes and Regulatory Factors}

Glycosylphosphatidylinositol anchored high density lipoprotein binding protein 1 (GPIHBP1) is a member of the lymphocyte antigen 6 family and plays a key role in the transport and localization of lipoprotein lipase (LPL) (48). The expression level of GPIHBP1 is much higher in breast tissue than that in other tissues, there was a strong correlation between the SNP of the GPIHBP1 promoter region and milk fat rate $\left(P=5.0^{\mathrm{E}-18}\right)(23)$. After overexpression or interference GPIHBP1, the expressions of ACACA and FASN in BMECs are significantly up-regulated or down-regulated (49). Fatty acid elongase 6 (ELOVL6) plays an important role in transcriptional regulation of lipid metabolism and adipocyte proliferation in ruminants (50). Overexpression or interference ELOVL6 can promote the expression of FASN in BMECs and also has positive regulatory effects on insulininduced genes (INSIG1 and INSIG2), SREBP1 and PPARG. So, we hypothesized that ELOVL6 could rely on transcription factors INSIG, SREBP1 and PPARG to regulate FASN (51). cAMP responsive element binding protein 1 (CREB1) is a member of the leucine zipper transcription factor family of DNA binding proteins, which is involved in the regulation of cellular lipid metabolism (52). The expression of CREB1 in rodents is closely related to the concentration of TAG (53). CREB1 overexpression significantly increases the mRNA abundance of SREBP1, ACACA and FASN in GMECs (54), which is similar to that in 3T3-L1 cells (55). Huang et al. (56) found that EGFR positively regulated FASN and ACACA in de novo synthesis of FA in GMECs through AKT and PLC- $\gamma-1$ pathways. LPL is the central factor in the hydrolysis of TAG and the uptake of free FA from plasma in very low density lipoproteins (VLDL) (57), the expression of LPL in early lactation is significantly higher than that in dry period, but the expression of LPL is relatively lower in peak and metaphase of lactation than that in early lactation. Knockout of LPL can reduce the expression of FASN, ACACA, PPARG and SREBF1 in GMECs (58).

\section{NEGATIVE REGULATION OF DE NOVO SYNTHESIS OF FA}

\section{t10c12-CLA}

t10c12-CLA can reduce TAG storage and enhance FA oxidation (106), which is beneficial to human health (59). After 5 days of 
perfusion of t10c12-CLA (13.6 g/d) into the abomasum of dairy cows, the fat production capacity of dairy cows decreased by $82 \%$. The mRNA abundance of FASN and ACACA also decreased by 40 and $39 \%$, respectively (60), which was consistent with the results of adding t10c12-CLA to the diet of dairy goats (61). The decrease of milk fat caused by t10c12-CLA can be alleviated by adding palmitic acid (62). At the cellular level, 150 $\mathrm{mol} / \mathrm{L}$ t10c12-CLA treatment of BMECs for $48 \mathrm{~h}$ significantly reduced MCFA and unsaturated fatty acid (USFA) content by 17.1 and $26.5 \%$, respectively, and mRNA abundance of FASN and ACACA (63), this negative regulatory effect was accomplished in part by inhibiting SREBP1 activity (64) or activating the AMPK signaling pathway (65). This result was further confirmed by Zhang et al. (66). In summary, the inhibitory effect of t10c12CLA on the de novo synthesis of milk fat in ruminants has been verified by a large amount of experimental data at both cellular and nutritional levels, and it is noteworthy that SREBP1 plays a key direct or indirect role in both milk fat inhibition and synthesis, further confirming the central position of SREBP1 in milk fat metabolism.

\section{LPS}

Lipopolysaccharide (LPS), as the main component of the outer membrane of Gram-negative bacteria, is a key factor in inducing the release of pro-inflammatory cytokines (67). Previous studies have shown that LPS-mediated inflammation is associated with milk fat inhibition syndrome in lactating cows (68). Liu et al. (69) have shown that LPS can reduce the expression of FASN and ACACA in BMECs, which inhibit the de novo synthesis of FA. 14-3-3 $\gamma$ is an important member of the 14-3-3 family and plays an important role in coordinating cell development (70). Overexpression 14-3-3 $\gamma$ reduces LPS-induced cytotoxicity and improves cell survival. The expression levels of ACACA and FASN were significantly up-regulated in cells with high expression of 14-3-3 $\gamma$ protein, the opposite results appeared after siRNA interference, suggesting that high levels of 14-3-3 $\gamma$ protein reduce LPS-induced cell damage and promote milk fat synthesis by increasing cell viability and upregulating the expression of transcription factors related to milk fat synthesis (71). SREBP1 is not only the central regulator of milk fat synthesis (72), but also is involved in the adaptive response of breast infection and is important in the regulation of inflammation (73). Wang et al. (74) showed that the milk fat inhibition with timedependent of BMECs induced by LPS was achieved by reducing the expression of SREBP1. The above results suggest that 14-3-3 $\gamma$ can alleviate the milk fat inhibition of BMECs induced by LPS, and this inhibition depends on SREBP1.

\section{INSIG}

Insulin inducible genes INSIG1 and INSIG2 are located in endoplasmic reticulum and play an important role in regulating lipid metabolism (75). The mRNA abundance of INSIG1 in breast tissue during peak lactation period was lower than that in dry period, which reveal the potential importance of INSIG in milk fat metabolism (76). After overexpression INSIG1 or INSIG2 in GMECs, the expression of ACACA and FASN was down-regulated, the content of TAG and total cholesterol (TC) were decreased. When INSIG1 and INSIG2 was interfered simultaneously, the contents of TAG and TC and lipid accumulation were significantly increased and ACACA expression was significantly up-regulated (77), It is shown that INSIG protein plays an important biological role in maintaining lipid homeostasis in goats, however, it is not known whether INSIG plays a similar function in milk lipid synthesis in cattle.

\section{AMPK and PTEN}

AMP-activated protein kinase (AMPK) is a heterotrimeric energy-sensitive protein. Its activation reduces lipid synthesis in the liver tissues of many species (78). After BMECs was treated with AMPK activator, ACACA gene was inactivated, even though the expression of FASN increased, the de novo synthesis of FA decreased, suggesting that AMPK is more sensitive to ACACA (79). The latest research shows that activating AMPK can significantly increase phosphorylation of ACACA (144\%), which further confirm that AMPK can inhibit the de novo synthesis of FA (80). In addition, sodium butyrate can relieve the inhibitory effect of AMPK on milk fat synthesis (81). Phosphatase and tensin homolog (PTEN) is a well-known tumor suppressor in non-ruminants, which regulates a variety of cellular processes through dephosphorylation of inositol phosphate substrates. Compared with the dry period, the mRNA abundance of PTEN decreased by $51.5 \%$ during the peak lactation period of goats, overexpression PTEN could significantly down-regulate the mRNA abundance of FASN and ACACA in GMECs (82), which suggest that there may be some mechanism in the mammary gland to reduce the expression of PTEN during lactation, thus weakening the inhibition on de novo synthesis of milk fat.

In summary, most of the identified and validated regulatory factors so far have positive regulatory functions in the de novo synthesis of milk fat in ruminant livestock. Interestingly, the expression levels of these positive regulators were higher in lactation than that in dry period, while the negative regulators showed the opposite trend, suggesting that some mechanism may exist in ruminants to balance the expression abundance of positive and negative regulators during different lactation periods, the exact mechanism is still unclear. The above studies also fully confirm the overwhelming scientific evidence for the role of SREBP 1 in the control of milk fat synthesis and repression, RPL8, ubiquitination, LXR, LPL, LPS and CREB1 play important roles in the control of SREBF1 expression. In addition, we find that mTOR/eIF4E, AKT/PLC- $\gamma$ - 1 and AMPK signaling pathways are pivotal in the de novo synthesis of milk lipids in ruminants (Figure 2).

\section{LCFA UPTAKE AND ACTIVATION}

De novo synthesis of FA and uptake LCFA from blood are the main ways of milk fat synthesis in mammals. For dairy cows in the first month of lactation, the intake of LCFA from the blood is dominant (6). Very low density lipoprotein receptor (VLDLR) cooperates with LPL to hydrolyze TAG in VLDL in blood and release LCFA (83). After entering the extracellular environment, LCFA is actively absorbed by MECs through fatty acid transferase (CD36) and fatty acid transporter (SLC27A), and another part 


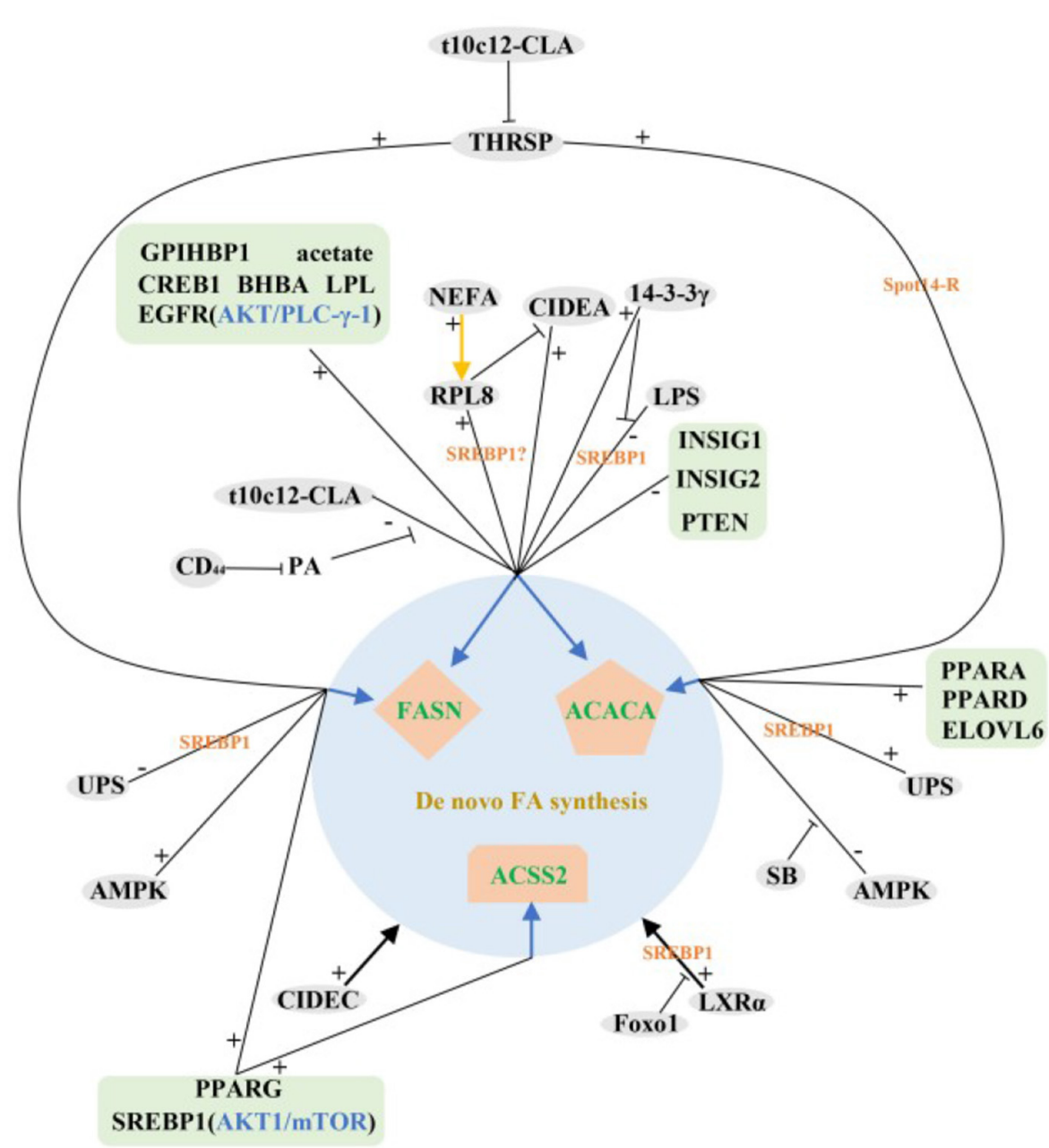

FIGURE 2 | Regulatory network of de novo milk fat synthesis in ruminants. +: Positive regulation; -: Negative regulation; $\longrightarrow$ : Inhibition; $\longrightarrow:$ It can regulate FASN, ACACA and ACSS2 genes; $\longrightarrow$ : Regulate a gene.

of LCFA enters MECs through the mechanism of Flip-flop. The LCFA enters MECs through the above two ways will be activated by long chain acyl-CoA synthetase (ACSL) (84).

Previous studies have shown that THRSP has a positive regulatory role in the de novo synthesis of milk fat in goats, THRSP negatively regulates the expression of CD36 when LCFA is taken up from the blood, reflecting the dynamic balancing role of THRSP in milk fat synthesis (85). Adipose triglyceride lipase (ATGL) also negatively regulates the expression of CD36 (86), since ATGL is a key enzyme in the hydrolysis of TAG to produce diacylglycerol and free fatty acids and regulates lipid storage and release in adipocytes, ATGL may be more involved in the catabolism of milk lipids. The mRNA abundance of CD36 was down-regulated by $56 \%$ after interfering PPARA in GMECs, which was the same as the positive regulatory effect of PPARA in the de novo synthesis of milk fat, however, interfering PPARA up-regulated the mRNA abundance of ACSL1 and also significantly increased TAG content, suggesting a stronger negative regulation of ACSL1 by PPARA and further interpreting the dominance of LCFA uptake in the blood (37). Several studies have confirmed that t10c12-CLA, PPARG and PPARD exhibit positive regulation of both $\operatorname{CD} 36(35,87,106)$ and ACSL1 (34, 36, 63), however, Shi et al. (61) challenge the above view that t10c12-CLA A positively regulates CD36 and ACSL1, which may be related to factors such as the species, mode and amount of additives, the exact mechanism of action needs to be further verified by more in-depth experimental studies as well as large-scale populations. As previously described, 14-3$3 \gamma$, LXR, SREBP1 and CIDEC have positive regulatory roles in the de novo synthesis of milk fat, which perform similar functions during LCFA uptake $(21,29,36,69)$. The SLC27 family (SLC27A1 to SLC27A6) is considered to be bifunctional proteins with LCFA transport and acyl-CoA synthetase activity. SLC27A6 known as FATP6 and ACSVL2 is a transporter colocated with CD36 and mediates LCFA uptake (88). Knockdown of SREBP1 in GMECs significantly reduced SLC27A6 gene expression, and LXR agonists in turn upregulated SLC27A6 mRNA abundance, suggesting that LXR may be involved in 


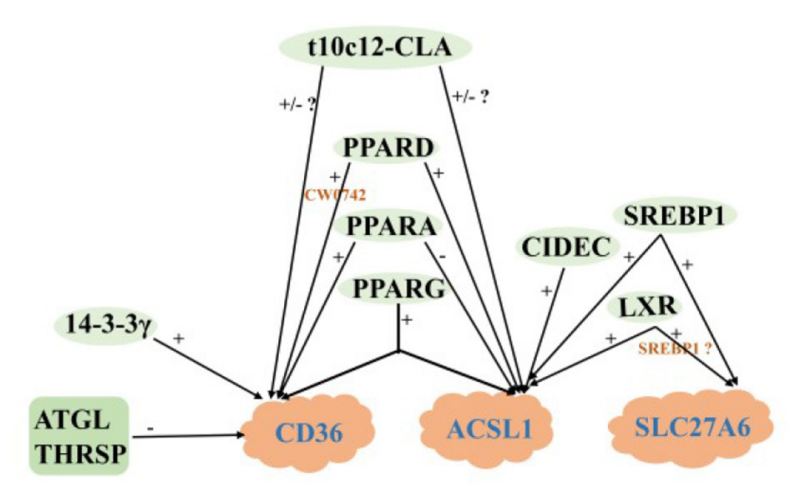

FIGURE 3 | Regulatory network of LCFA uptake and activation in ruminants. + : Positive regulation; -: Negative regulation.

regulating SLC27A6 gene expression in GMECs with an SREBP1dependent manner $(21,29)$.

In a word, MECs involves many genes and key regulatory factors in the uptake of LCFA in blood, most of them have positive regulatory effects. At present, the mechanism of $\mathrm{t} 10 \mathrm{c} 12$ CLA regulating CD36 and ACSL1 remain not clear, and the research on the regulation mechanism of ruminant SLC27A6 is still lacking (Figure 3).

\section{LCFA TRANSPORT AND DESATURATION}

\section{FABP3 Is a Specific Transporter of LCFA}

The activated LCFA requires specific transporters to diffuse quickly and freely in cells (89). Acyl coenzyme A binding protein $(\mathrm{ACBP})$ is the main intracellular transporter of acylCoA in mammalian tissues (90), ACBP plays little role in milk fat synthesis in ruminants, which is supported by mouse data (91). Fatty acid binding protein (FABP) is a series of lipid chaperone proteins. The central cavity of the protein can bind LCFA and other hydrophobic ligands, which played an important role in LCFA uptake, transport, maintenance of cellular lipid homeostasis and regulation of fat storage (92). There are at least nine protein types of FABP in mammals. Except for FABP2, all FABP subtypes exist in the mammary gland of dairy cows. The mRNA abundance of FABP3 is the highest, and the expression of FABP3 is up-regulated during lactation (93). Therefore, the LCFA synthesized from de novo by FA and released from the blood mainly binds to FABP3 when activated in the cell (11).

AMPK is a heterotrimeric complex, which is composed of a catalytic subunit $(\alpha)$ and two regulatory subunits ( $\beta$ and $\gamma)$. It regulates lipid metabolism mainly by modifying the transcription of adipogenic genes and participating in posttranslational modification of key enzymes in lipid synthesis (78). The activation of AMPK can increase the expression of FABP3 and the oxidation of FA in muscle cells (94). After BMECs were treated with AMPK activator ( $600 \mu \mathrm{M}$ AICAR), the expression of FABP3 and SREBP1 increased by 56 and 66\%, respectively (79). However, reducing the proportion of mature SREBP1c and milk fat synthesis by $19 \%$ after AMPK activation, suggesting that
AMPK may have a stronger effect on SREBP1c (80). Ubiquitin plays an important role in the de novo synthesis of FA in dairy cow mammary glands. When the activity of UPS was inhibited, the expression level of FABP3 and the content of LCFA were increased significantly (95). In addition, PPARD, PPARA and t10c12-CLA were also negative regulations of $\operatorname{FABP} 3(36,37,61)$, while LXR, SREBP1, RPL8, CREB1, ELOVL7, and PPARG were positively regulated of FABP3 $(21,24,34,54,96,97)$, and the regulation of LXR depended on SREBP1.

\section{Desaturation of SCD1}

SCD1 is a rate-limiting enzyme in the biosynthesis of monounsaturated fatty acids (MUFA), which catalyzes the formation of $\Delta 9$ unsaturated carbon double bonds (C16:1 or C18:1) (98). It is also a key enzyme in the endogenous synthesis of t10c12-CLA (99).

Identified Key transcription factors to regulate lipid synthesis including PPARs (100), SREBP (101), and LXR (102). PPARG was positively correlated with SCD1 expression in the mammary gland of goats during peak lactation (103), and overexpression PPARG1, PPARG2, and PPARA significantly upregulated SCD1 expression (37), which was also confirmed in cattle (34). Overexpression of SREBP1 enhanced the expression of SCD1 and its promoter activity in GMECs, while silenced SREBP1 reduced the expression of SCD1 and its promoter activity in GMECs (104), suggesting that SREBP1 regulates SCD1 expression at the transcriptional level. Meanwhile, $\operatorname{LXR} \alpha$ can upregulate the mRNA abundance of SREBP1, and thus indirectly regulate the expression of SCD1 and promote the synthesis of MUFA and TAG in GMECs $(29,104)$. In addition, ELOVL6, EGFR and THRSP also have positively regulated SCD1. The regulation of SCD1 by EGFR depends on the AKT- and PLC- $\gamma-1$ signaling pathways $(38,51,56)$.

After BMECs was treated with $150 \mathrm{~mol} / \mathrm{L} \mathrm{t10c12-CLA}$ for $48 \mathrm{~h}$, the abundance of SCD1 decreased significantly (63). T10c12CLA could also inhibit SCD1 expression by affecting the binding of SREBP1 protein to SRE and NF-Y sites (105), which was consistent with Zhang et al. (106) and Peterson et al. (64). Foxo1 can inhibit the participation of SREBP1 in lipid metabolism in the liver of mice. For dairy cows, Foxol also has a negative regulatory effect on the SCD1 (30). In addition, PTEN, INSIG1, and INSIG2 negatively regulate the expression of SCD1 in milk fat synthesis $(77,82)$.

In summary, LXR, SREBP1, PPARG, PPARA and t10c12CLA act together on FABP3 and SCD1. Among them, LXR, SREBP1 and PPARG positively regulate the expression of FABP3 and SCD1, while t10c12-CLA is the opposite. LXR participates in regulating the expression of FABP3 and SCD1 by SREBP1 (Figure 4).

\section{TAG SYNTHESIS}

Dihydroxyacetone phosphate (DHAP) produced by glycolysis produces glycerol-3-phosphate in the presence of glycerol3-phosphate dehydrogenase (GPDH). A phosphate group was added to glycerol-3-phosphate under the action of glycerol-3-phosphate acyltransferase (GPAM), and then LCFA 


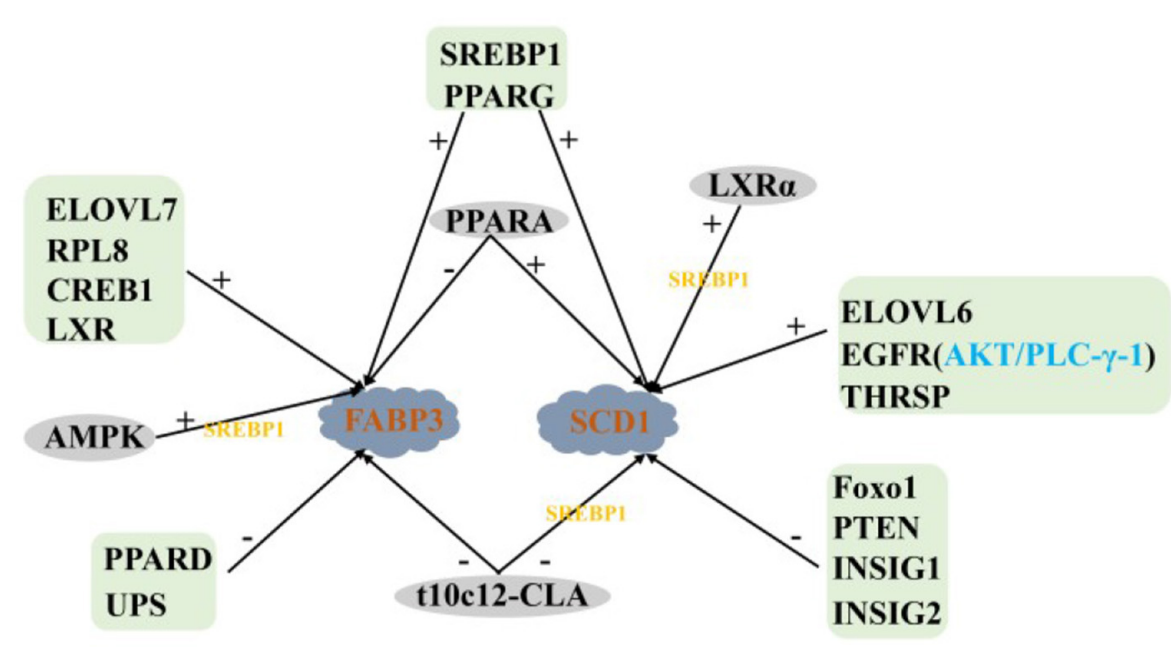

FIGURE 4 | Regulatory network of LCFA transport and desaturation in milk fat synthesis of ruminants. +: Positive regulation; -: Negative regulation.

was activated to form lysophosphatidic acid (LPA). The LPA becomes the substrate of 1-acylglycerol-3-phosphate-Oacyltransferase (AGPAT) to form phosphatidic acid (PA). Phosphatidyl phosphatase (LPIN) catalyzes the formation of 1,2diacylglycerol (DAG) from PA, and adds a third LCFA through DGAT1 to form a TAG molecule.

\section{Positive Regulation of TAG Synthesis}

AGPAT6, DGAT1, LPIN, and GPAM are four key enzymes that regulate TAG synthesis in the endoplasmic reticulum of mammary glands. Their expression levels in the mammary glands of lactating cows are significantly higher than that in dry period dairy cows (12). LXR and CREB1 positively regulate the transcription of AGPAT6, DGAT1, LPIN, and GPAM genes in GMECs, and the regulatory role of LXR is dependent on SREBP1 $(29,54)$. PPARG positively regulates the expression of LPIN1, AGPAT6, and DGAT1 in buffalo and goat mammary glands $(35,107,108)$. The expression of AGPAT6 and DGAT1 remain upregulated after overexpression of PPARG1, PPARG2 (33), and PPARA (37), respectively, in GMECs, PPARG1 is more abundant in mammary tissues, suggesting that PPARG1 may be a more important isoform in ruminant TAG synthesis. In contrast, PPARD knockdown increase the expression of AGPAT6 and DGAT1 and TAG content in GMECs, which is consistent with the negative regulatory effect of PPARD on the FABP3 gene (36). Specific protein 1 (SP1) is a zinc finger transcription factor, the expression abundance of AGPAT6, LPIN1, and DGAT1 were significantly decreased after silencing SP1 in GMECs. However, the expression of AGPAT6 and LPIN1 did not change significantly when SP1 was overexpressed by adenovirus. The expression of DGAT1 is still significantly down-regulated, which suggest that the decreased expression of DGAT1 may be the main reason for the inhibition of lipid accumulation in MECs (109). In addition, the DGAT1 gene is positively regulated by CIDEC and RPL8 in BMECs $(24,47)$.
AKT serine/threonine kinase is the intermediate of phosphatidylinositol 3-kinase/AKT (PI3K/AKT) signaling pathway, which regulates a series of biological processes including glucose transport, glycolysis, cell survival, protein, and fat synthesis (110). Activated AKT can regulate the expression of adipogenic genes in animal liver and fat (111). The content of TAG is increased by phosphorylation AKT1 and SREBP1 upregulated by mTOR in GMECs. Inhibition AKT/mTOR signal pathway can down-regulate the expression of AGPAT6, DGAT1 and GPAM (22). It is suggest that AKT1 plays an important role in regulating GMECs TAG synthesis, which may be through the mTOR/SREBP1 axis. Shi et al. (112) showed that inhibition ELOVL6 in GMECs significantly reduced GPAM expression and TAG concentration, ELOVL6 similarly positively regulated GPAM and AGPAT6 expression in buffalo MECs, suggesting that ELOVL6 not only regulates fatty acid chain extension and is involved in the de novo synthesis of FA, but also has a positive regulatory role in TAG synthesis (51). In addition, the GPAM is also positively regulated by THRSP in GMECs (38).

\section{Negative Regulation of TAG Synthesis}

Baumgard et al. (60) found that the expression of the AGPAT6 decreased significantly after infusion t10c12-CLA into the abomasum of dairy cows in 5 days, which consistent with Zhu et al. (113) interfering with FASN in GMECs. Previous studies have shown that INSIG1 can effectively block the proteolysis activation of SREBP family members (114) and play an important role in de novo milk fat synthesis in ruminants (50). Fan et al. (76) measured the protein abundance of INSIG1 in the mammary gland of buffalo during peak lactation and dry period, and found that the expression of INSIG1 in the peak lactation period was lower than that in the dry period, and the overexpression INSIG1 significantly decreased the expression of GPAM and AGPAT6. The opposite result was obtained after INSIG1 was knockout, which was also confirmed by Li et al. (77). The above data provide 
strong support for the key role of INSIG1 in regulating milk fat synthesis in ruminants.

In summary, the regulatory network of TAG synthesis in ruminant MECs is very complex, in which the PPARs family seems to play a very important role. Among the four key enzymes in TAG synthesis, there are still few reports on the regulation of LPIN and GPAM (Figure 5).

\section{LIPID DROPLET SECRETION}

TAG forms between the two lobules of the endoplasmic reticulum and play an important role in the formation of lipid droplets. The extracellular secretion of lipid droplets is accomplished by the cooperation among adipose differentiation-associated protein (PLIN2/ADFP), xanthine dehydrogenase (XDH) and butyrophilin subfamily 1 member A1 (BTN1A1) (86).

\section{Regulation of PLIN2}

Most of the milk fat produced during lactation is secreted into milk through the membrane wrapping process of cytoplasmic lipid droplets (115). PLIN2 is a cytoplasmic lipid droplet (CLD) binding protein (116). Shi et al. (117) found that overexpression PLIN2 can increase the lipid accumulation and TAG concentration of GMECs, and oleic acid (OA) supplementation can enhance its co-localization with CLD surface. In OA-free GMECs, PLIN2 knockout cannot eliminate lipid accumulation at the morphological level, suggesting that some other compensatory factors may assistant the formation of CLD. In summary, PLIN2 plays an important role in the formation of CLD in GMECs.

In non-ruminants, fatty acid elongase 5 (ELOVL5) is the key enzyme for the endogenous synthesis of unsaturated fatty acids (112). Compared with dry period and late lactation, the expression of ELOVL5 is the lowest in the goat mammary

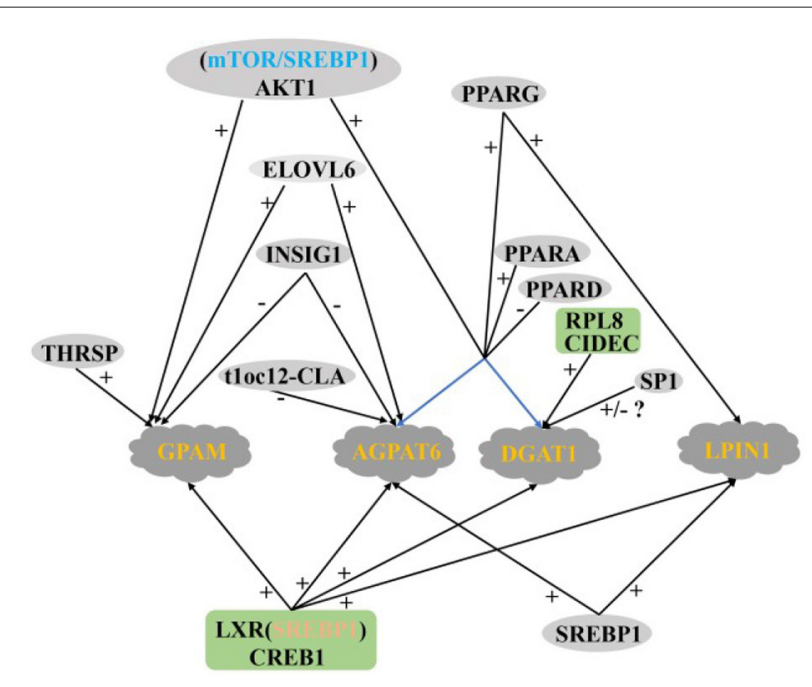

FIGURE 5 | Regulatory network of key genes in ruminant MECs TAG synthesis. +: Positive regulation; -: Negative regulation. gland during the peak lactation, and the overexpression and interference of ELOVL5 positively regulate the expression of PLIN2. However, the content of TAG does not change, which may be due to an insufficient supply of substrates, finally affects the synthesis of milk fat in vitro (118). Previous studies have confirmed that SP1 is involved in the regulation of FA synthesis in humans (119), rats (120) and goats (121). Exogenous $\alpha$-linolenic acid enhanced the binding of bovine SP1 to the proximal promoter of fatty acid elongase 7 (ELOVL7), resulting in the accumulation of lipid droplets in BMECs (122). After overexpression or interference SP1, the expression of PLIN2 decreased significantly (25\%), and the content of lipid droplets secreted by GMECs decreased significantly by 9 and $8.5 \%$, respectively (109). On the contrary, the expression of PLIN2 was significantly up-regulated after activation or knockout of PPARG in GMECs (107), indicating that other compensating factors are still a part of the regulation of PLIN2. In addition, PPARD, ATGL, and FASN positively regulate PLIN2 in milk fat synthesis of ruminants $(36,86,113)$.

\section{Regulation of XDH and BTN1A1}

Milk lipid droplets (LD) are the main components of membrane lipid secretion (123). When BTN1A1 was knockout, LD content decreased (124). In the process of secretion activation, $\mathrm{XDH}$ located in the apical membrane of MECs interacts with the cytoplasmic domain of BTN1A1 to regulate milk fat secretion (125). Compared with the dry period, the expression of XDH and BTN1A1 in the mammary gland of dairy cows was significantly up-regulated at the beginning of lactation (126). For different breeds, the expression level of XDH and BTN1A1 in mammary glands of lactating cows was significantly higher than those of yaks (12), which may also be one of the reasons for the high milk production of cows. Shi et al. (61) found that adding t10c12-CLA to the diet could significantly reduce the percentage of milk fat and the expression of BTN1A1 in dairy

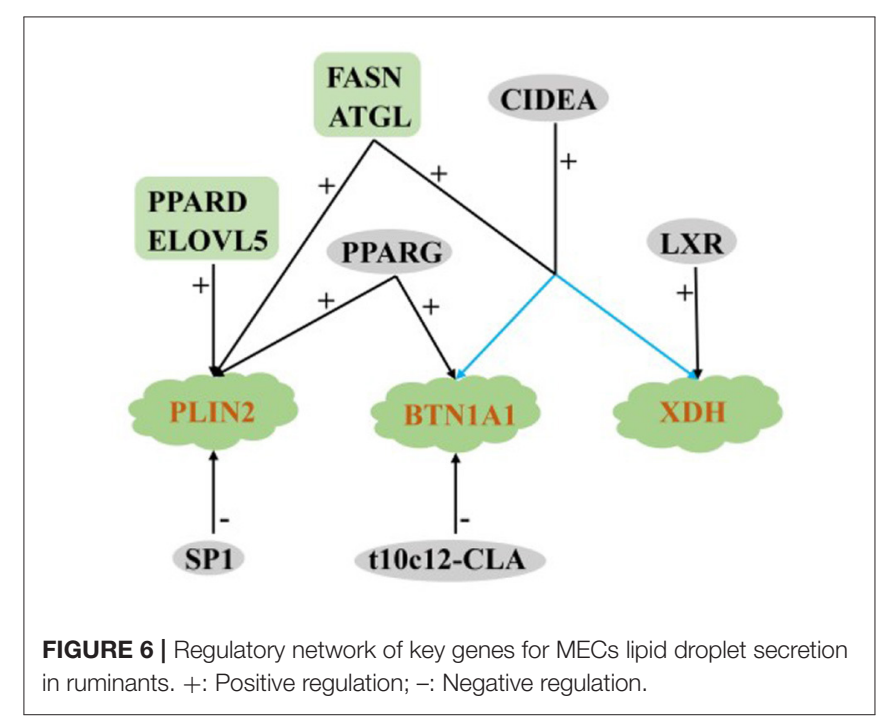


TABLE 1 | Regulatory relationships of key genes for milk fat synthesis in ruminant livestock.

\begin{tabular}{|c|c|c|c|}
\hline Item & Key gene & Positive regulation factor & Negative regulation factor \\
\hline \multirow{3}{*}{$\begin{array}{l}\text { De novo synthesis of } \\
\text { FA }\end{array}$} & ACSS2 & SREBP1, LXR $\alpha$, PPARG, CIDEC & \\
\hline & FASN & $\begin{array}{l}\text { SREBP1, RPL8, LXR } \alpha \text {, PPARG, PPARD, PPARA, THRSP, CIDEA, } \\
\text { GPIHBP1, ELOVL6, CREB1, EGFR, LPL }\end{array}$ & $\begin{array}{l}\text { Foxo1, t10c12-CLA, LPS, INSIG1, INSIG2, } \\
\text { AMPK, PTEN }\end{array}$ \\
\hline & ACACA & SREBP1, UPS, LXR $\alpha$, THRSP, CIDEA, GPIHBP1, CREB1, EGFR, ACACA & t10c12-CLA, LPS, INSIG1, INSIG2, AMPK, PTE \\
\hline \multirow[t]{3}{*}{ LCFA uptake in blood } & CD36 & PPARA, PPARG, PPARD, $14-3-3 \gamma$ & THRSP, ATGL \\
\hline & SLC27A6 & SREBP1, LXR & \\
\hline & ACSL1 & PPARG, PPARD, LXR, SREBP1, CIDEC & PPARA \\
\hline \multirow{2}{*}{$\begin{array}{l}\text { LCFA transport and } \\
\text { desaturation }\end{array}$} & FABP3 & AMPK, LXR, SREBP1, RPL8, CREB1, ELOVL7, PPARG & UPS, PPARD, PPARA, t10c12-CLA \\
\hline & SCD1 & PPARG1, PPARG2, PPARA, SREBP1, LXR $\alpha$, ELOVL6, EGFR, THRSP & t10c12-CLA, Foxo1, PTEN, INSIG1, INSIG2 \\
\hline \multirow[t]{4}{*}{ TAG synthesis } & AGPAT6 & LXR, CREB1, PPARG, PPARA, SP1, AKT1, ELOVL6 & PPARD, t10c12-CLA, INSIG1 \\
\hline & DGAT1 & LXR, CREB1, PPARG, PPARA, SP1, AKT1 & PPARD \\
\hline & LPIN1 & LXR, CREB1, PPARG, SP1 & \\
\hline & GPAM & LXR, CREB1, AKT1, ELOVL6, THRSP & INSIG1 \\
\hline \multirow[t]{3}{*}{ Lipid droplet secretion } & PLIN2 & ELOVL5, PPARG, PPARD, ATGL, FASN & SP1 \\
\hline & $\mathrm{XDH}$ & FASN, ATGL, CIDEA, LXR & \\
\hline & BTN1A1 & PPARG, FASN, ATGL, CIDEA & t10c12-CLA \\
\hline
\end{tabular}

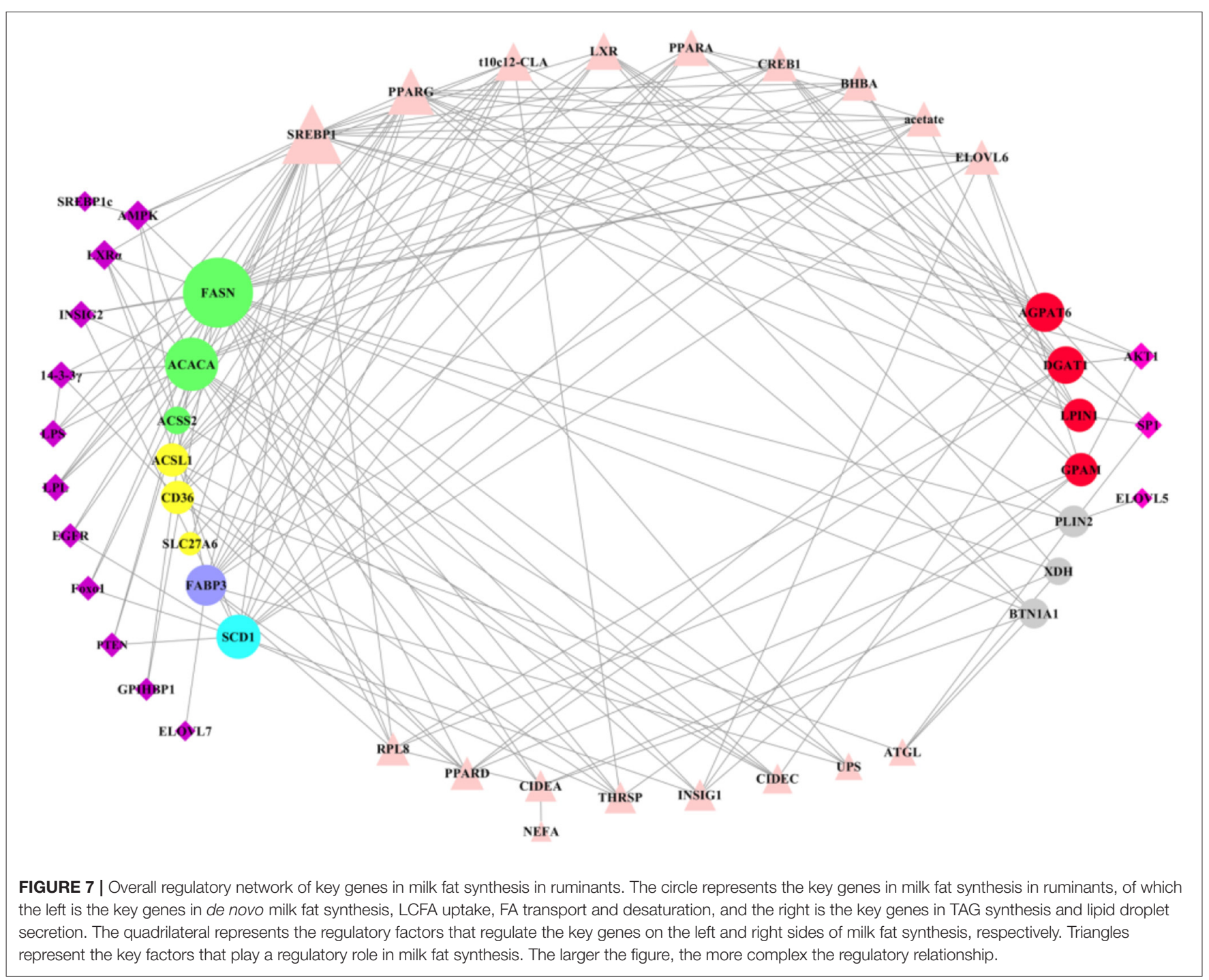


goats. Knockout/overexpression PPARG significantly downregulated/upregulated the expression of BTN1A1 in buffalo (35). In addition, FASN, ATGL, CIDEA and LXR positively regulated the expression of $\mathrm{XDH}$ and Btn1a1 in ruminants $(29,45,86,113)$.

The above studies show that among the many regulatory factors, only ATGL and FASN have positive regulatory effects on the key genes PLIN2, XDH, and BTN1A1in lipid droplet secretion, reflecting their important role in fat droplet secretion in ruminants. Only SP1 and t10c12-CLA could significantly reduce lipid droplet secretion in ruminants, and other regulatory factors had positive regulatory effects (Figure 6).

\section{SUMMARY}

Most of many key factors have the positive regulation in milk fat synthesis, expression of these regulatory factors was higher in lactation than that in dry period, which may be a reflection of the balance of milk fat (Table 1). After clearly understanding the regulatory patterns of key genes in milk fat synthesis, we used the software Cytoscape3.7.2 to construct a network interaction map between all key genes and regulatory factors (Figure 7). Regulatory factors AMPK, LXR $\alpha$, INSIG2, 14-3-3 $\gamma$, LPS, LPL, EGFR, Foxo1, PTEN, CPIHBP1, ELOVL7, and SREBP1c have specific regulatory effects on key genes in the early stage of milk fat synthesis (de novo synthesis of FA, LCFA uptake in blood, LCFA transport and desaturation). Only AKT1, SP1, and ELOVL5 have specific regulatory effects in the later stage of milk fat synthesis (TAG synthesis and lipid droplet secretion). However, the regulatory effects of these specific regulators are not fixed, and, likely, some functions have not been explored yet, and more functions will be explored in the process of accumulating and updating the experimental data in the future to supplement or correct the existing data. In addition, SREBP1 plays a central role in maintaining essential transcription of genes related to milk fat synthesis, and PPARG, t10c12-CLA, and LXR also appear the critical importance. The results of t10c12-CLA regulation of CD36 and ACSL1 in LCFA uptake and activation remain controversial, which may be related to such as the species studied, the mode and the amount of additives. t10c12-CLA showed significant repressive effects in all other processes of milk fat synthesis. Both PPARG and LXR showed positive regulatory effects in milk fat synthesis, and LXR was involved in regulating milk fat synthesis in ruminant livestock with an SREBP1-dependent manner. It is noteworthy that there is a paucity of studies on the regulatory mechanisms of genes

\section{REFERENCES}

1. Wiley AS. The globalization of cow's milk production and consumption: biocultural perspectives. Ecol Food Nutr. (2007) 46:281-312. doi: 10.1080/03670240701407657

2. Li D, Xie XJ, Wang J, Bian YJ, Li QZ, Gao XJ, et al. MiR-486 regulates lactation and targets the PTEN gene in cow mammary glands. PLoS ONE. (2015) 10:e118284. doi: 10.1371/journal.pone.0118284

3. Chen Z, Chu S, Wang X, Fan Y, Zhan T, Arbab AAI, et al. MicroRNA-106b regulates milk fat metabolism via ATP binding cassette subfamily A member related to LCFA uptake and lipid droplet secretion in blood, and further in-depth investigation of them is necessary.

Overall, our survey of the literature shows that the regulation of milk fat synthesis in ruminants is controlled by a complex network of transcription factors and signaling proteins. With the factors involved in transcriptional and post-transcriptional regulatory networks are revealed, more precise interventions using transcription factor networks in combination with diet and feeding management may be more effective for milk quality improvement. It is also worthwhile to ponder that many important transcriptional regulators regulating milk fat synthesis in ruminants have been identified and confirmed in current studies, however, most of the findings seem to be isolated, and the order, strength and location of the regulators' roles in milk fat synthesis and the specific mechanisms by which MECs perceive an increase or decrease in milk fat remain unknown. Therefore, in future research, it is necessary for researchers to further explore the specific mechanism of regulatory factors and the interaction between them. Furthermore, milk fat synthesis in milk is a very complex regulatory mechanism, which not only including the simple expression of a relatively small number of genes encoding major proteins, but also is the product of complex interactions between multiple organs in the animal.

Therefore, the using of an integrated systems biology approach seems to be important for understanding milk fat synthesis.

\section{AUTHOR CONTRIBUTIONS}

TM: article writing. $\mathrm{YM}$ and $\mathrm{HH}$ : literature query and sentence modification. XF and JZ: article grammar modification. YG: conceptual analysis and writing-review and editing. All authors contributed to the article and approved the submitted version.

\section{FUNDING}

This project was supported by the special breeding project of high-quality and high yield dairy cows in the Ningxia Autonomous region (Grant No: 2019NYYZ05).

\section{ACKNOWLEDGMENTS}

Thank to all the teachers who helped with this experiment and to all the authors of this paper for their hard work.

1 (ABCA1) in bovine mammary epithelial cells. J Agr Food Chem. (2019) 67:3981-90. doi: 10.1021/acs.jafc.9b00622

4. Kuipers RS, Graaf D, Luxwolda MF, Muskiet M, Dijckbrouwer D, Muskiet F. Saturated fat, carbohydrates and cardiovascular disease. Neth J Med. (2011) 69:372-8. doi: 10.1111/j.1708-8305.2011. 00541.x

5. Shen BL, Han S, Wang YX, Yang ZN, Zou ZW, Liu J, et al. BtamiR-152 affects intracellular triglyceride content by targeting the UCP3 gene. J Anim Physiol An N. (2019) 103:1365-73. doi: 10.1111/jpn. 13162 
6. Bauman DE, Mather IH, Wall RJ, Lock AL. Major advances associated with the biosynthesis of milk. J Dairy Sci. (2006) 89:1235-43. doi: 10.3168/jds.S0022-0302(06)72192-0

7. Keenan TW, Mather IH. Intracellular origin of milk fat globules and the nature of the milk fat globule membrane. Springer US. (2006) 2:13771. doi: 10.1007/0-387-28813-9_4

8. Xu B, Gerin I, Miao HZ, Vu-Phan D, Johnson CN, Xu RC, et al. Multiple roles for the non-coding RNA SRA in regulation of adipogenesis and insulin sensitivity. PLoS ONE. (2010) 5:e14199. doi: 10.1371/journal.pone.0014199

9. Lucena R, Gallego M, Cárdenas S, Valcárcel M. Autoanalyzer for milk quality control based on the lactose, fat, and total protein contents. Anal Chem. (2003) 75:1425-9. doi: 10.1021/ac020553n

10. Osorio JS, Lohakare J, Bionaz M. Biosynthesis of milk fat, protein, and lactose: roles of transcriptional and posttranscriptional regulation. Physiol Genomics. (2016) 48:231-56. doi: 10.1152/physiolgenomics.000 16.2015

11. Bionaz M, Loor JJ. Gene networks driving bovine milk fat synthesis during the lactation cycle. BMC Genomics. (2008) 9:366. doi: 10.1186/1471-2164-9-366

12. Lee JN, Yong Wang $\mathrm{Y}, \mathrm{Xu}$ YO, Li YC, Tian F, Jiang MF. Characterisation of gene expression related to milk fat synthesis in the mammary tissue of lactating yaks. J Dairy Res. (2017) 84:283-8. doi: 10.1017/S0022029917000413

13. Laliotis GP, Bizelis I, Rogdakis E. Comparative approach of the de novo fatty acid synthesis (lipogenesis) between ruminant and non ruminant mammalian species: from biochemical level to the main regulatory lipogenic genes. Curr Genomics. (2010) 11:168-83. doi: 10.2174/138920210791110960

14. Urrutia NL, Harvatine KJ. Effect of conjugated linoleic acid and acetate on milk fat synthesis and adipose lipogenesis in lactating dairy cows. J Dairy Sci. (2017) 100:1-13. doi: 10.3168/jds.2016-12369

15. Urrutia NL, Harvatine KJ. Acetate dose-dependently stimulates milk fat synthesis in lactating dairy cows. J Nutr. (2017) 147:763-9. doi: 10.3945/jn.116.245001

16. Ali I, Li C, Li L, Kuang M, Wang G. Effect of acetate, $\beta$-hydroxybutyrate and their interaction on lipogenic gene expression, triglyceride contents and lipid droplet formation in dairy cow mammary epithelial cells. In Vitro Cell Dev An. (2021) 57:66-75. doi: 10.1007/s11626-020-00538-2

17. Yan QX, Tang SX, Zhou CS, Han XF, Tan ZL. Effects of free fatty acids with different chain lengths and degrees of saturability on the milk fat synthesis in primary cultured bovine mammary epithelial cells. J Agr Food Chem. (2019) 67:8485-92. doi: 10.1021/acs.jafc.9b02905

18. Zhao YL, Guo XY, Yan SM, Shi BL, Sheng R. Acetate regulates milk fat synthesis through the mammalian target of rapamycin/eukaryotic initiation factor $4 \mathrm{E}$ signaling pathway in bovine mammary epithelial cells. J Dairy Sci. (2021) 104:337-45. doi: 10.3168/jds.2020-18246

19. Young-Ah M. The SCAP/SREBP pathway: a mediator of hepatic steatosis. Endocrinol Metab. (2017) 32:6-10. doi: 10.3803/EnM.2017.32.1.6

20. Ma L, Corl BA. Transcriptional regulation of lipid synthesis in bovine mammary epithelial cells by sterol regulatory element binding protein-1. $J$ Dairy Sci. (2012) 95:3743-55. doi: 10.3168/jds.2011-5083

21. Xu HF, Luo J, Tian HB, Li J, Zhang XY, Chen Z, et al. Rapid communication: lipid metabolic gene expression and triacylglycerol accumulation in goat mammary epithelial cells are decreased by inhibition of SREBP-1. J Anim Sci. (2018) 96:2399-407. doi: 10.1093/jas/sky069

22. Zhang T, Huang J, Yi Y, Zhang X, Loor JJ, Cao Y, et al. Akt serine/threonine kinase 1 regulates de novo fatty acid synthesis through the mammalian target of rapamycin/sterol regulatory element binding protein 1 axis in dairy goat mammary epithelial cells. J Agr Food Chem. (2018) 66:1197205. doi: 10.1021/acs.jafc.7b05305

23. Li N, Zhao F, Wei CJ, Liang MY, Zhang N, Wang CM, et al. Function of SREBP1 in the milk fat synthesis of dairy cow mammary epithelial cells. Int J Mol Sci. (2014) 15:16998-7013. doi: 10.3390/ijms150916998

24. Zheng XR, Jiang L, Ning C, Hu ZZ, Zhou L, Yu Y, et al. A novel mutation in the promoter region of RPL8 regulates milk fat traits in dairy cattle by binding transcription factor Pax6. BBA Mol Cell Biol L. (2019) 1864:158528. doi: 10.1016/j.bbalip.2019.158528
25. Han Y, Hu Z, Cui A, Liu Z, Ma F, Xue Y. Post-translational regulation of lipogenesis via AMPK-dependent phosphorylation of insulin-induced gene. Nat Commun. (2019) 10:623. doi: 10.1038/s41467-019-08585-4

26. Punga T, Bengoechea-Alonso MT, Ericsson J. Phosphorylation and ubiquitination of the transcription factor sterol regulatory element-binding protein-1 in response to DNA binding. J Biol Chem. (2006) 281:2527886. doi: 10.1074/jbc.M604983200

27. Liu L, Zhang Q. Identification and functional analysis of candidate gene VPS28 for milk fat in bovine mammary epithelial cells. Biochem Bioph Res Co. (2019) 510:606-13. doi: 10.1016/j.bbrc.2019.01.016

28. Kashiwagi K, Mai Y, Matsui D, Tanaka M, Sugimoto K, Chiba H, et al. Expression of liver X receptors in normal and refractory carcinoma tissues of the human lung and pancreas. Histol Histopathol. (2018) 33:497-505. doi: 10.14670/HH-11-949

29. Xu HF, Luo J, Zhang XY, Li J, Bionaz M. Activation of liver X receptor promotes fatty acid synthesis in goat mammary epithelial cells via modulation of SREBP1 expression. J Dairy Sci. (2019) 102:354455. doi: 10.3168/jds.2018-15538

30. He Q, Luo J, Wu J, Yao W, Li Z, Wang H. FoxO1 knockdown promotes fatty acid synthesis via modulating SREBP1 activities in the dairy goat mammary epithelial cells. J Agr Food Chem. (2020) 68:1206778. doi: 10.1021/acs.jafc.0c05237

31. Bionaz M, Chen S, Khan MJ, Loor JJ. Functional role of PPARs in ruminants: potential targets for fine-tuning metabolism during growth and lactation. PPAR Res. (2013) 2013:684159. doi: 10.1155/2013/684159

32. Huang DG, Zhao QL, Liu HF, Guo YJ, Xu HG. PPAR- $\alpha$ Agonist WY14643 inhibits LPS-induced inflammation in dynovial fibroblasts via NF-kB pathway. J Mol Neurosci. (2016) 59:1-10. doi: 10.1007/s12031-016-0775-y

33. Shi HB, Zhao WS, Luo J, Yao DW, Sun YT, Li J, et al. Peroxisome proliferatoractivated receptor $\gamma 1$ and $\gamma 2$ isoforms alter lipogenic gene networks in goat mammary epithelial cells to different extents. J Dairy Sci. (2014) 97:543747. doi: 10.3168/jds.2013-7863

34. Liu LL, Lin Y, Liu LX, Wang LN, Bian YJ, Gao XJ, et al. Regulation of peroxisome proliferator-activated receptor gamma on milk fat synthesis in dairy cow mammary epithelial cells. In Vitro Cell Dev Biol Anim. (2016) 52:1044-59. doi: 10.1007/s11626-016-0059-4

35. Zhou FT, Ouyang YN, Miao YW. Peroxisome proliferator-activated receptor gamma regulates genes involved in milk fat synthesis in mammary epithelial cells of water buffalo. Anim Sci J. (2021) 92:e13537. doi: 10.1111/asj.13537

36. Shi HB, Zhang $\mathrm{CH}$, Zhao W, Luo J, Loor JJ. Peroxisome proliferatoractivated receptor delta facilitates lipid secretion and catabolism of fatty acids in dairy goat mammary epithelial cells. J Dairy Sci. (2017) 100:797806. doi: 10.3168/jds.2016-11647

37. Tian HB, Luo J, Shi HB, Chen XY, Wu J, Liang YS, et al. Role of peroxisome proliferator-activated receptor- $\alpha$ on the synthesis of monounsaturated fatty acids in goat mammary epithelial cells. J Anim Sci. (2020) 98:skaa062. doi: 10.1093/jas/skaa062

38. Yao DW, Luo J, He QY, Wu M, Shi HB, Wang H, et al. Thyroid hormone responsive (THRSP) promotes the synthesis of medium-chain fatty acids in goat mammary epithelial cells. J Dairy Sci. (2016) 99:312433. doi: 10.3168/jds.2015-10632

39. Cui YJ, Liu ZY, Sun X, Hou XM, Qu B, Zhao F, et al. Thyroid hormone responsive protein spot 14 enhances lipogenesis in bovine mammary epithelial cells. In Vitro Cell Dev Biol Anim. (2015) 51:58694. doi: 10.1007/s11626-014-9865-8

40. Kim CW, Moon YA, Park SW, Cheng D, Kwon HJ, Horton JD. Induced polymerization of mammalian acetyl-CoA carboxylase by MIG12 provides a tertiary level of regulation of fatty acid synthesis. Proc Natl Acad Sci USA. (2010) 107:9626-31. doi: 10.1073/pnas.1001292107

41. Harvatine KJ, Bauman DE. SREBP1 and thyroid hormone responsive spot 14 (S14) are involved in the regulation of bovine mammary lipid synthesis during diet-induced milk fat depression and treatment with CLA. J Nutr. (2006) 136:2468-74. doi: 10.1093/jn/136.10.2468

42. Zhou ZH, Toh SY, Chen ZM, Guo K, Ng CP, Ponniah S, et al. Cidea-deficient mice have lean phenotype and are resistant to obesity. Nat Genet. (2003) 35:49-56. doi: 10.1038/ng1225 
43. Zhou LK, Xu L, Ye J, Li D, Wang WS, Li XH, et al. Cidea promotes hepatic steatosis by sensing dietary fatty acids. Hepatology. (2012) 56:95107. doi: 10.1002/hep.25611

44. Wang WS, Lv N, Zhang SS, Shui GG, Qian H, Zhang JF, et al. Cidea is an essential transcriptional coactivator regulating mammary gland secretion of milk lipids. Nat Med. (2012) 18:235-43. doi: 10.1038/nm.2614

45. Sun XD, Wang YZ, Loor JJ, Bucktrout R, Xin Shu X, Jia HD, et al. High expression of cell death-inducing DFFA-like effector a (CIDEA) promotes milk fat content in dairy cows with clinical ketosis. J Dairy Sci. (2019) 102:1682-92. doi: 10.3168/jds.2018-15439

46. Tan JS, Seow CJ, Goh VJ, Silver DL. Recent advances in understanding proteins involved in lipid droplet formation, growth and fusion. J Genet Genomics. (2014) 41:251-9. doi: 10.1016/j.jgg.2014.03.003

47. Yang Y, Lin Y, Duan X, Lv H, Xing W, Li Q, et al. The effects of cell death-inducing DNA fragmentation factor- $\alpha$-like effector C (CIDEC) on milk lipid synthesis in mammary glands of dairy cows. J Dairy Sci. (2017) 100:4014-24. doi: 10.3168/jds.2016-11549

48. Young SG, Zechner R. Biochemistry and pathophysiology of intravascular and intracellular lipolysis. Genes Dev. (2013) 27:459-84. doi: 10.1101/gad.209296.112

49. Yang J, Liu X, Wang D, Ning C, Wang HF, Zhang Q, et al. Functional validation of GPIHBP1 and identification of a functional mutation in GPIHBP1 for milk fat traits in dairy cattle. Sci Rep. (2017) 7:8546. doi: 10.1038/s41598-017-08668-6

50. Junjvlieke Z, Mei CG, Khan R, Zhang WZ, Hong JY, Wang L, et al. Transcriptional regulation of bovine elongation of very long chain fatty acids protein 6 in lipid metabolism and adipocyte proliferation. J Cell Biochem. (2019) 120:13932-43. doi: 10.1002/jcb.28667

51. Fan X, Zhu W, Qiu L, Zhang G, Zhang Y, Miao Y. Elongase of very long chain fatty acids 6 (ELOVL6) promotes lipid synthesis in buffalo mammary epithelial cells. J Anim Physiol Anim Nutr. (2021) 111. doi: 10.1111/jpn.13536. [Epub ahead of print].

52. Herzig S, Hedrick S, Morantte I, Koo SH, Galimi F, Montminy M, et al. CREB controls hepatic lipid metabolism through nuclear hormone receptor PPAR-gamma. Nature. (2003) 426:190-3. doi: 10.1038/nature02110

53. Erion DM, Ignatova ID, Yonemitsu S, Nagai Y, Chatterjee P, Weismann $\mathrm{D}$, et al. Prevention of hepatic steatosis and hepatic insulin resistance by knockdown of cAMP response element-binding protein. Cell Metab. (2009) 10:499-506. doi: 10.1016/j.cmet.2009.10.007

54. Yao DW, Yang CL, Ma J, Chen LL, Luo J, Ma Y, et al. cAMP response element binding protein 1 (CREB1) promotes monounsaturated fatty acid synthesis and triacylglycerol accumulation in goat mammary epithelial cells. Animals. (2020) 10:1871. doi: 10.3390/ani10101871

55. Reusch J, Colton LA, Klemm DJ. CREB activation induces adipogenesis in 3T3-L1 cells. Mol Cell Biol. (2000) 20:100820. doi: 10.1128/MCB.20.3.1008-1020.2000

56. Huang JT, Dai BG, Qu HX, Zhong YL, Ma Y, Luo J. Epidermal growth factor stimulates fatty acid synthesis mainly via PLC- $\gamma 1 /$ Akt signaling pathway in dairy goat mammary epithelial cells. Animals. (2020) 10:930. doi: 10.3390/ani10060930

57. Bernard L, Leroux C, Chilliard Y. Expression and nutritional regulation of lipogenic genes in the ruminant lactating mammary gland. Adv Exp Med Biol. (2008) 606:67-108. doi: 10.1007/978-0-387-74087-4_2

58. Zhao WS, Hu SL, Yu K, Wang H, Wang W, Loor J, et al. Lipoprotein lipase, tissue expression and effects on genes related to fatty acid synthesis in goat mammary epithelial cells. Int J Mol Sci. (2014) 15:2275771. doi: 10.3390/ijms151222757

59. Suárez-Vega A, Gutiérrez-Gil B, Toral PG, Hervás G, Arranz JJ, Frutos $\mathrm{P}$, et al. Conjugated linoleic acid (CLA)-induced milk fat depression: application of RNA-Seq technology to elucidate mammary gene regulation in dairy ewes. Sci Rep. (2019) 9:4473. doi: 10.1038/s41598-019-40881-3

60. Baumgard LH, Matitashvili E, Corl BA, Dwyer DA, Bauman DE. trans-10, cis-12 conjugated linoleic acid decreases lipogenic rates and expression of genes involved in milk lipid synthesis in dairy cows. J Dairy Sci. (2002) 85:2155-63. doi: 10.3168/jds.S0022-0302(02)74294-X

61. Shi HP, Zhang TY, Li C, Wang JJ, Huang JT, Li ZY. Trans-10, cis-12 conjugated linoleic acid affects expression of lipogenic genes in mammary gland of lactating dairy goats. J Agric Food Chem. (2017) 65:94607. doi: 10.1021/acs.jafc.7b02377

62. Granados-Rivera LD, Hernández-Mendo O, González-Muñoz SS, Burgueño-Ferreira JA, Mendoza-Martínez GD, Arriaga-Jordán CM. Effect of palmitic acid on the mitigation of milk fat depression syndrome caused by trans-10, cis-12-conjugated linoleic acid in grazing dairy cows. Arch Anim Nutr. (2017) 71:1-13. doi: 10.1080/1745039X.2017.1379165

63. Wang HF, Liu HY, Liu JX, Zhao K, Wang C, Yang W. High-level exogenous trans10, cis12 conjugated linoleic acid plays an anti-lipogenesis role in bovine mammary epithelial cells. Anim Sci J. (2014) 85:74450. doi: 10.1111/asj.12204

64. Peterson DG, Matitashvili EA, Bauman DE. The inhibitory effect of trans-10, cis-12 CLA on lipid synthesis in bovine mammary epithelial cells involves reduced proteolytic activation of the transcription factor SREBP-1. J Nutr. (2004) 134:2523-7. doi: 10.1093/jn/134.10.2523

65. Kim Y, Kim J, Whang KY, Park Y. Impact of conjugated linoleic acid (CLA) on skeletal muscle metabolism. Lipids. (2016) 51:15978. doi: 10.1007/s11745-015-4115-8

66. Zhang TY, Huang JT, Tian HB, Ma Y, Chen Z, Wang JJ, et al. Trans-10, cis -12 conjugated linoleic acid alters lipid metabolism of goat mammary epithelial cells by regulation of de novo synthesis and the AMPK signaling pathway. J Dairy Sci. (2018) 101:5571-81. doi: 10.3168/jds.2017-12822

67. Wu YJ, Sun YW, Zhang Z, Chen JC, Dong GZ. Effects of peptidoglycan, lipoteichoic acid and lipopolysaccharide on inflammation, proliferation and milk fat synthesis in bovine mammary epithelial cells. Toxins. (2020) 12:497. doi: 10.3390/toxins12080497

68. Waggoner JW, Löest CA, Turner JL, Mathis CP, Hallford DM. Effects of dietary protein and bacterial lipopolysaccharide infusion on nitrogen metabolism and hormonal responses of growing beef steers1. J Anim Sci. (2009) 87:3656-68. doi: 10.2527/jas.2009-2011

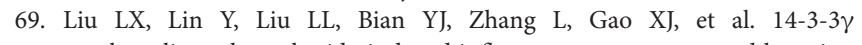
regulates lipopolysaccharide-induced inflammatory responses and lactation in dairy cow mammary epithelial cells by inhibiting NF- $\mathrm{B}$ and MAPKs and up-regulating mTOR signaling. Int J Mol Sci. (2015) 16:1662241. doi: 10.3390/ijms160716622

70. Hemert M, Steensma HY, Heusden G. 14-3-3 proteins: key regulators of cell division, signalling and apoptosis. Bioessays. (2010) 23:93646. doi: 10.1002/bies.1134

71. Liu LX, Zhang L, Lin YE, Bian YJ, Gao XJ, Qu BO, et al. 14-3-3 $\gamma$ regulates cell viability and milk fat synthesis in lipopolysaccharide-induced dairy cow mammary epithelial cells. Exp Ther Med. (2016) 11:127987. doi: 10.3892/etm.2016.3029

72. Genini S, Badaoui B, Sclep G, Bishop SC, Giuffra E. Strengthening insights into host responses to mastitis infection in ruminants by combining heterogeneous microarray data sources. BMC Genomics. (2011) 12:225. doi: 10.1186/1471-2164-12-225

73. Oishi Y, Spann NJ, Link VM, Muse ED, Strid T, Edillor C, et al. SREBP1 contributes to resolution of pro-inflammatory TLR4 signaling by reprogramming fatty acid metabolism. Cell Metab. (2017) 25:41227. doi: 10.1016/j.cmet.2016.11.009

74. Wang J, Zhang X, He X, Yang B, Wang H, Shan X, et al. LPS-induced reduction of triglyceride synthesis and secretion in dairy cow mammary epithelial cells via decreased SREBP1 expression and activity. J Dairy Res. (2018) 85:439-44. doi: 10.1017/S0022029918000547

75. Bionaz M, Thering BJ, Loor JJ. Fine metabolic regulation in ruminants via nutrient-gene interactions: saturated long-chain fatty acids increase expression of genes involved in lipid metabolism and immune response partly through PPAR- $\alpha$ activation. Br J Nutr. (2012) 107:179-91. doi: 10.1017/S0007114511002777

76. Fan X, Qiu L, Teng X, Zhang Y, Miao Y. Effect of INSIG1 on the milk fat synthesis of buffalo mammary epithelial cells. J Dairy Res. (2020) 87:34955. doi: 10.1017/S0022029920000710

77. Li C, Wang M, Zhang TY, He QY, Shi HP, Luo J, et al. Insulin-induced gene 1 and 2 isoforms synergistically regulate triacylglycerol accumulation, lipid droplet formation, and lipogenic gene expression in goat mammary epithelial cells. J Dairy Sci. (2018) 102:1736-46. doi: 10.3168/jds.201815492 
78. Hardie DG, Schaffer BE, Brunet A. AMPK: an energy-sensing pathway with multiple inputs and outputs. Trends Cell Biol. (2015) 26:190201. doi: 10.1016/j.tcb.2015.10.013

79. Mcfadden JW, Corl BA. Activation of AMP-activated protein kinase (AMPK) inhibits fatty acid synthesis in bovine mammary epithelial cells. Biochem Biophys Res Commun. (2009) 390:388-93. doi: 10.1016/j.bbrc.2009.09.017

80. Huang J, Guesthier MA, Burgos SA. AMP-activated protein kinase controls lipid and lactose synthesis in bovine mammary epithelial cells. J Dairy Sci. (2019) 103:340-51. doi: 10.3168/jds.2019-16343

81. Cheng J, Zhang Y, Ge Y, Li W, Liu J, Qu Y, et al. Sodium butyrate promotes milk fat synthesis in bovine mammary epithelial cells via GPR41 and its downstream signalling pathways. Life Sci. (2020) 259:118375. doi: 10.1016/j.lfs.2020.118375

82. Yao DW, Ma J, Yang CL, Chen LL, He QY, Coleman DN, et al. Phosphatase and tensin homolog (PTEN) suppresses triacylglycerol accumulation and monounsaturated fatty acid synthesis in goat mammary epithelial cells. $J$ Dairy Sci. (2021) 104:7283-94. doi: 10.3168/jds.2020-18784

83. Bionaz M, Loor JJ. Gene networks driving bovine mammary protein synthesis during the lactation cycle. Bioinform Biol Insights. (2011) 5:8398. doi: 10.4137/BBI.S7003

84. Doege H, Stahl A. Protein-mediated fatty acid uptake: novel insights from in vivo models. Physiology. (2006) 21:259-68. doi: 10.1152/physiol.00014.2006

85. Wu J, Wang C, Li S, Li S, Wang W, Li J, et al. Thyroid hormone-responsive SPOT 14 homolog promotes hepatic lipogenesis, and its expression is regulated by Liver X receptor $\alpha$ through a sterol regulatory element-binding protein 1c-dependent mechanism in mice. Hepatology. (2013) 58:61728. doi: 10.1002/hep. 26272

86. Li J, Luo J, Wang H, Shi HB, Zhu JJ, Sun YT, et al. Adipose triglyceride lipase regulates lipid metabolism in dairy goat mammary epithelial cells. Gene. (2015) 554:125-30. doi: 10.1016/j.gene.2014.10.020

87. Shi HB, Zhang $\mathrm{CH}, \mathrm{Xu}$ ZA, Lou GG, Liu JX, Luo J, et al. Peroxisome proliferator-activated receptor delta regulates lipid droplet formation and transport in goat mammary epithelial cells. J Dairy Sci. (2018) 101:26419. doi: 10.3168/jds.2017-13543

88. Yen MC, Chou SK, Kan JY, Kuo PL, Hou MF, Hsu YL. New insight on solute carrier family 27 member 6 (SLC27A6) in tumoral and non- tumoral breast cells. Int J Med Sci. (2019) 16:366-75. doi: 10.7150/ijms.29946

89. Mcarthur MJ, Atshaves BP, Frolov A, Foxworth WD, Schroeder F. Cellular uptake and intracellular trafficking of long chain fatty acids. J Lipid Res. (1999) 40:1371-83.

90. Frolov A, Cho TH, Murphy EJ, Schroeder F. Isoforms of rat liver fatty acid binding protein differ in structure and affinity for fatty acids and fatty acyl CoAs. Biochemistry. (1997) 36:6545-55. doi: 10.1021/bi970205t

91. Rudolph MC, Mcmanaman JL, Phang T, Russell T, Kominsky DJ, Serkova NJ, et al. Metabolic regulation in the lactating mammary gland: a lipid synthesizing machine. Physiol Genomics. (2007) 28:32336. doi: 10.1152/physiolgenomics.00020.2006

92. Zhang YR, Zhang JM, Ren YH, Lu RH, Yang LP, Nie GX, et al. Tracing the evolution of fatty acid-binding proteins (FABPs) in organisms with a heterogeneous fat distribution. FEBS Open Bio. (2020) 10:86172. doi: $10.1002 / 2211-5463.12840$

93. Liang MY, Hou XM, Qu B, Zhang N, Li N, Cui YJ, et al. Functional analysis of FABP3 in the milk fat synthesis signaling pathway of dairy cow mammary epithelial cells. In Vitro Cell Dev Biol Anim. (2014) 50:86573. doi: 10.1007/s11626-014-9780-z

94. Lee WJ, Kim M, Park HS, Kim HS, Jeon MJ, Oh KS, et al. AMPK activation increases fatty acid oxidation in skeletal muscle by activating PPARalpha and PGC-1. Biochem Biophys Res Commun. (2006) 340:2915. doi: 10.1016/j.bbrc.2005.12.011

95. Liu LL, Guo AW, Wu PF, Chen FF, Yang YJ, Qin Z. Regulation of VPS28 gene knockdown on the milk fat synthesis in Chinese Holstein dairy. Hereditas. (2018) 40:1092-100. doi: 10.16288/j.yczz.18-134

96. Mcfadden JW, Corl BA. Activation of liver X receptor (LXR) enhances de novo fatty acid synthesis in bovine mammary epithelial cells. J Dairy Sci. (2010) 93:4651-8. doi: 10.3168/jds.2010-3202

97. Shi HB, Wang L, Luo J, Liu JX, Loor JJ, Liu HY. Fatty acid elongase 7 (ELOVL7) plays a role in the synthesis of long-chain unsaturated fatty acids in goat mammary epithelial cells. Animals. (2019) 9:389. doi: 10.3390/ani9060389

98. Bernard L, Rouel J, Leroux C, Ferlay A, Faulconnier Y, Legrand $\mathrm{P}$, et al. Mammary lipid metabolism and milk fatty acid secretion in alpine goats fed vegetable lipids. J Dairy Sci. (2005) 88:147889. doi: $10.3168 /$ jds.S0022-0302(05)72816-2

99. Tian HB, Luo J, Zhang ZF, Wu J, Zhang TY, Busato S, et al. CRISPR/Cas9mediated stearoyl-CoA desaturase 1 (SCD1) deficiency affects fatty acid metabolism in goat mammary epithelial cells. J Agric Food Chem. (2018) 66:10041-52. doi: 10.1021/acs.jafc.8b03545

100. Clarke SD. Polyunsaturated fatty acid regulation of gene transcription: a molecular mechanism to improve the metabolic syndrome. J Nutr. (2001) 131:1129-32. doi: 10.1093/jn/131.4.1129

101. Eberle D, Hegarty B, Bossard P, Ferre P, Foufelle F. SREBP transcription factors: master regulators of lipid homeostasis. Biochimie. (2004) 86:83948. doi: 10.1016/j.biochi.2004.09.018

102. Ulven SM, Dalen KT, Gustafsson JK, Nebb HI. LXR is crucial in lipid metabolism. Prostaglandins Leukot Essent Fatty Acids. (2005) 73:5963. doi: 10.1016/j.plefa.2005.04.009

103. Shi HB, Luo J, Yao DW, Zhu JJ, Xu HF, Shi HP, et al. Peroxisome proliferatoractivated receptor- $\gamma$ stimulates the synthesis of monounsaturated fatty acids in dairy goat mammary epithelial cells via the control of stearoylcoenzyme A desaturase. J Dairy Sci. (2013) 96:7844-53. doi: 10.3168/jds.20 13-7105

104. Yao DW, Luo J, He QY, Xu HF, Li J, Shi HB, et al. Liver X receptor $\alpha$ promotes the synthesis of monounsaturated fatty acids in goat mammary epithelial cells via the control of stearoyl-coenzyme A desaturase 1 in an SREBP-1-dependent manner. J Dairy Sci. (2016) 99:6391402. doi: 10.3168/jds.2016-10990

105. Zhang TY, Li C, Huang L, Song N, Cao YH, Loor JJ, et al. Regulation of stearoyl-coenzyme A desaturase 1 by trans-10, cis-12 conjugated linoleic acid via SREBP1 in primary goat mammary epithelial cells. J Agric Food Chem. (2019) 67:1463-9. doi: 10.1021/acs.jafc.8b06358

106. Zhang TY, Ma Y, Wang H, Loor JJ, Xu HF, Shi HP, et al. Trans10, cis12 conjugated linoleic acid increases triacylglycerol accumulation in goat mammary epithelial cells in vitro. Anim Sci J. (2017) 89:43240. doi: 10.1111/asj.12935

107. Shi HB, Luo J, Zhu JJ, Li J, Sun YT, Lin XZ, et al. PPAR $\gamma$ regulates genes involved in triacylglycerol synthesis and secretion in mammary gland epithelial cells of dairy goats. PPAR Res. (2013) 2013:310948. doi: 10.1155/2013/310948

108. Vargas-Bello-Pérez E, Zhao W, Bionaz M, Luo J, Loor JJ. Nutrigenomic effect of saturated and unsaturated long chain fatty acids on lipid-related genes in goat mammary epithelial cells: what is the role of PPAR $\gamma$. Vet Sci. (2019) 6:54. doi: 10.3390/vetsci6020054

109. Zhu JJ, Luo J, $\mathrm{Xu} \mathrm{HF}$, Wang $\mathrm{H}$, Loor JJ. Short communication: altered expression of specificity protein 1 impairs milk fat synthesis in goat mammary epithelial cells. J Dairy Sci. (2016) 99:5965. doi: 10.3168/jds.2016-99-7-5965

110. Whiteman EL, Han C, Birnbaum MJ. Role of AKT/protein kinase B in metabolism. Trends Endocrinol Metab. (2003) 13:444-51. doi: 10.1016/S1043-2760(02)00662-8

111. Yecies JL, Zhang HH, Menon S, Liu S, Yecies D, Lipovsky AI, et al. Akt stimulates hepatic SREBP1c and lipogenesis through parallel mTORC1-dependent and independent pathways. Cell Metab. (2011) 14:2132. doi: 10.1016/j.cmet.2011.06.002

112. Shi $\mathrm{HB}, \mathrm{Wu} \mathrm{M}$, Zhu JJ, Zhang CH, Yao DW, Luo J, et al. Fatty acid elongase 6 plays a role in the synthesis of long-chain fatty acids in goat mammary epithelial cells. J Dairy Sci. (2017) 100:4987-95. doi: 10.3168/jds.2016-12159

113. Zhu JJ, Luo J, Sun YT, Shi HB, Li J, Wu M, et al. Short communication: effect of inhibition of fatty acid synthase on triglyceride accumulation and effect on lipid metabolism genes in goat mammary epithelial cells. J Dairy Sci. (2015) 98:3485-91. doi: 10.3168/jds.2014-8202

114. Carobbio S, Hagen RM, Lelliott CJ, Slawik M, Medina-Gomez G, Tan CY, et al. Adaptive changes of the insig1/SREBP1/SCD1 set point help adipose tissue to cope with increased storage demands of obesity. Diabetes. (2013) 62:3697-708. doi: 10.2337/db12-1748 
115. Chong BM, Reigan P, Mayle-Combs KD, Orlicky DJ, Mcmanaman JL. Determinants of adipophilin function in milk lipid formation and secretion. Trends Endocrinol Metab. (2011) 22:211-7. doi: 10.1016/j.tem.2011.04.003

116. Listenberger LL, Ostermeyer-Fay AG, Goldberg EB, Brown WJ, Brown DA. Adipocyte differentiation-related protein reduces lipid droplet association of adipose triglyceride lipase and slows triacylglycerol turnover. J Lipid Res. (2007) 48:2751-61. doi: 10.1194/jlr.M700359-JLR200

117. Shi HB, Yu K, Luo J, Li J, Tian HB, Zhu JJ, et al. Adipocyte differentiationrelated protein promotes lipid accumulation in goat mammary epithelial cells. J Dairy Sci. (2015) 98:6954-64. doi: 10.3168/jds.2015-9452

118. Shi $\mathrm{HB}, \mathrm{Du} \mathrm{Y}$, Zhang $\mathrm{CH}$, Sun $\mathrm{C}$, He YL, Wu YH, et al. Fatty acid elongase 5 (ELOVL5) alters the synthesis of long-chain unsaturated fatty acids in goat mammary epithelial cells. J Dairy Sci. (2018) 101:458694. doi: 10.3168/jds.2017-14061

119. Lu SY, Archer MC. Sp1 coordinately regulates de novo lipogenesis and proliferation in cancer cells. Int J Cancer. (2010) 126:41625. doi: 10.1002/ijc. 24761

120. Jeon BN, Kim YS, Choi WI, Koh DI, Kim MK, Yoon JH, et al. Krpok increases FASN expression by modulating the DNA binding of SREBP-1c and Sp1 at the proximal promoter. J Lipid Res. (2012) 53:75566. doi: 10.1194/jlr.M022178

121. Zhu JJ, Sun YT, Luo J, Wu M, Li JH, Cao YH. Specificity protein 1 regulates gene expression related to fatty acid metabolism in goat mammary epithelial cells. Int J Mol Sci. (2015) 16:1806-20. doi: 10.3390/ijms16011806

122. Chen S, Hu Z, He H, Liu X. Fatty acid elongase7 is regulated via SP1 and is involved in lipid accumulation in bovine mammary epithelial cells. J Cell Physiol. (2018) 233:4715-25. doi: 10.1002/jcp.26255

123. Ogg SL, Weldon AK, Dobbie L, Smith AJ, Mather IH. Expression of butyrophilin (Btnla1) in lactating mammary gland is essential for the regulated secretion of milk-lipid droplets. Proc Natl Acad Sci USA. (2004) 101:10084-9. doi: 10.1073/pnas.0402930101
124. Han L, Zhang M, Xing Z, Coleman DN, Yang G. Knockout of butyrophilin subfamily 1 member A1 (BTN1A1) alters lipid droplet formation and phospholipid composition in bovine mammary epithelial cells. J Anim Sci Biotechnol. (2020) 11:72. doi: 10.1186/s40104-02000479-6

125. Lee H, Padhi E, Hasegawa Y, Larke J, Parenti M, Wang A, et al. Compositional dynamics of the milk fat globule and its role in infant development. Front Pediatr. (2018) 6:313. doi: 10.3389/fped.2018. 00313

126. Jedrzejczak M, Szatkowska I. Bovine mammary epithelial cell cultures for the study of mammary gland functions. In Vitro Cell Dev Biol Anim. (2014) 50:389-98. doi: 10.1007/s11626-013-9711-4

Conflict of Interest: The authors declare that the research was conducted in the absence of any commercial or financial relationships that could be construed as a potential conflict of interest.

Publisher's Note: All claims expressed in this article are solely those of the authors and do not necessarily represent those of their affiliated organizations, or those of the publisher, the editors and the reviewers. Any product that may be evaluated in this article, or claim that may be made by its manufacturer, is not guaranteed or endorsed by the publisher.

Copyright (c) $2021 \mathrm{Mu}, \mathrm{Hu}, \mathrm{Ma}$, Feng, Zhang and Gu. This is an open-access article distributed under the terms of the Creative Commons Attribution License (CC BY). The use, distribution or reproduction in other forums is permitted, provided the original author(s) and the copyright owner(s) are credited and that the original publication in this journal is cited, in accordance with accepted academic practice. No use, distribution or reproduction is permitted which does not comply with these terms. 